\title{
National Prevalence of Obesity Prevalence of obesity in Portugal
}

\author{
I. do Carmo ${ }^{1-3}$, O. dos Santos², J. Camolas ${ }^{3}$, J. Vieira ${ }^{3}$, M. Carreira ${ }^{1}$, L. Medina ${ }^{4}$, L. Reis $^{4}$ and
}

A. Galvão-Teles ${ }^{1-3}$

${ }^{1}$ Faculdade de Medicina de Lisboa; ${ }^{2}$ Fundação Ciência e Tecnologia Scholar, Lisbon; ${ }^{3}$ Hospital Santa Maria, Lisbon; ${ }^{4}$ Faculdade de Medicina do Porto, Portugal

Received 30 May 2005; revised 23 September 2005; accepted 26 September 2005

Address for correspondence: Professor Dra. I do Carmo, Faculdade de Medicina de Lisboa, Av. Professor Egas Moniz, Lisboa 1649-028,

Portugal. E-mail: icarmo@netcabo.pt

\begin{abstract}
Summary
Obesity is a serious health problem in developed countries. Knowledge of reliable and nationwide representative data is a must for any public health action. The dimension of this problem in Portugal was first assessed in 1995-1998. A similar populational survey using objective anthropometric measures is now being conducted (field work started in January 2003). A total of 6411 subjects aged 1864 years old have already been measured and their respective body mass indexes (BMIs) calculated. Results from 2003 to 2005 show $38.6 \%$ is overweight and $13.8 \%$ has obesity. The total of overweight and obesity is $52.4 \%$. In $1995-1998$ survey, overweight was $35.2 \%$ and obesity was $14.4 \%$. The total was $49.6 \%$. These results suggest an increase of the overweight/obesity (altogether) prevalence in the last 10 years. Actual results show that more than half of the adult sample has excessive weight and $2.4 \%$ of the sample has low BMI. Finally, $45.6 \%$ of the sample suffers increased health risks because of high waist circumference $(\geq 80 \mathrm{~cm}$ for women; $\geq 94 \mathrm{~cm}$ for men). These results highlight the fact that, although obesity was identified as a public health problem one decade ago, action to reduce it does not seem to have been very effective to date.
\end{abstract}

Keywords: Obesity, Portugal, prevalence.

obesity reviews (2006) 7, 233-237

\section{Introduction}

Obesity prevalence in Iberian countries follows the increasing trend of other European countries $(1,2)$.

In Spain, a recent pooled analysis of regional anthropometric data collected between 1990 and 2000 indicates an obesity prevalence in adult population (9885 subjects aged $25-60$ years) of $14.5 \%$ (15.8\% for women and $13.4 \%$ for men) (3).

The last census (2001) revealed that Portugal has 10.4 million inhabitants (4). The population of this small European country is predominantly Caucasian and 30\% lives in two main cities (Lisbon and Porto), with the rest concentrated mainly along the littoral of the country. There are 324 family doctors per 100000 residents and life expectancy is around 77.1 years (80.6 for women and
73.7 for men). Social conditions have significantly improved since the 1970s and, as in other developed countries, the prevalence of overweight and obesity has increased as well.

This paper provides an overview of overweight and obesity prevalence in mainland Portugal. Some data are taken from the preliminary results of a nationwide representative survey using objective anthropometric measurements. Since both methodology and data-collecting instruments are similar to the ones from another survey $(5,6)$, findings are also compared with those reported one decade ago.

\section{Prevalence in 1995-1998}

This was the first nationwide face-to-face survey ever conducted in Portugal for assessing the prevalence of over- 
weight/obesity in the adult Portuguese population $(5,6)$. It used a randomized household sample based on the census of 1991. The sample was proportional to the population regarding age, gender and geographical distribution. In each household, every person aged 18-65 was interviewed and anthropometric measurements (weight, height, and waist and hips circumferences) were taken. In total, the body mass index (BMI) was calculated for 4328 people (2485 women and 1843 men). Table 1 shows the $1995-$ 1998 prevalence of overweight and obesity by gender. Almost half of the sample $(49.6 \%)$ was then registered as overweight/obese. As can be seen, overweight prevalence was higher among men $(41.1 \%)$ than among women $(30.8 \%)$. However, considering the categories of obesity altogether $(\mathrm{BMI}>30)$, the overall percentage was higher in women $(15.4 \%)$ than in men $(12.9 \%)$.

At this period, two other nationwide health surveys provided self-reported overweight/obesity prevalences for the Portuguese adult population (with more than 19 years old): the 1995-1996 and the 1998-1999 National Health Surveys (7). In both surveys, data collection was done through face-to-face interview with self-reported weight and height.

The most relevant epidemiological conclusion coming from those two National Health Surveys was the increase trend found for the overall overweight/obesity prevalences for both men and women (especially when considering the short period between assessments): from 50.2\% (in 19951996) to $54.0 \%$ (in 1998-1999) for men, and from $44.9 \%$ to $46.5 \%$ (respectively) for women.

It is interesting to note that prevalences coming from do Carmo et al. (5,6) (collected between 1995 and 1998) were higher than prevalences coming from the first National Health Survey (1995-1996) but quite similar to the prevalences coming from the second National Health Survey (1998-1999). It is not easy to make a clear interpretation of these comparisons. In the National Health Surveys, prevalences were based in self-report of weight and height while in the study conducted by Carmo et al., prevalences were based in objective measures of weight and height.

Table 1 Prevalence of BMI categories in adults (18-64 years old) in 1995-1998 survey

\begin{tabular}{|c|c|c|c|c|c|c|}
\hline & \multicolumn{2}{|c|}{ Women } & \multicolumn{2}{|l|}{ Men } & \multicolumn{2}{|l|}{ Total } \\
\hline & $n$ & $\%$ & $n$ & $\%$ & $n$ & $\%$ \\
\hline Low $(<18.5)$ & 98 & 3.9 & 14 & 0.8 & 112 & 2.6 \\
\hline Normal (18.5-24.9) & 1237 & 49.8 & 833 & 45.2 & 2070 & 47.8 \\
\hline Overweight (25.0-29.9) & 766 & 30.8 & 758 & 41.1 & 1524 & 35.2 \\
\hline Obesity I (30.0-34.9) & 303 & 12.2 & 209 & 11.3 & 512 & 11.8 \\
\hline Obesity II (35.0-39.9) & 55 & 2.2 & 22 & 1.2 & 77 & 1.8 \\
\hline Obesity III $(\geq 40.0)$ & 26 & 1.0 & 7 & 0.4 & 33 & 0.8 \\
\hline Total & 2485 & 100.0 & 1843 & 100.0 & 4328 & 100.0 \\
\hline
\end{tabular}

This methodological difference may partly explain the lower prevalences of 1995-1996 National Health Survey. And the fact that such difference disappeared when comparing data from 1998 to 1999 National Health Survey with data from do Carmo et al. might be explained with the increase of overweight/obesity prevalences (from 1995 till 1999).

\section{Prevalence in 2003-2005}

In 2003, a similar survey project was started and is still in the process of collecting data. It follows the same methodology defined for the study of 1995-1998 $(5,6)$ and the main goals are now (i) to determine the prevalence of overweight and obesity in the Portuguese mainland population; (ii) to determine the distribution of waist circumference; (iii) to study the association between BMI and nutritional and other life habits (daily physical activity, smoking habits, etc.) and (iv) to evaluate BMI development since the 1995 population-based study $(5,6)$.

Like the survey conducted in 1995-1998, this is an observational, cross-sectional and descriptive study. Data are collected using a standardized questionnaire in structured face-to-face interviews with anthropometric measurements (weight, height, and waist and hips circumferences). Data gathering started in January 2003 and is expected to be completed by the end of 2005 . When complete, it will be a representative random sample of adults aged 18-64 living in mainland Portugal.

Data collection follows a proportional stratified sampling procedure, considering population gender, age and geographical distribution. Within each district of Portugal, a first random selection of local areas was followed by random route sampling of households. In each household, every person between the ages of 18 and 64 was asked to participate in the study.

The questionnaire was also based on the one used in 1995-1998 survey. It is being presented as a life habits questionnaire. It starts with a set of demographic questions (including gender, age, family status, level of education, professional status and type of professional activity). This is followed by the Baecke Questionnaire of Habitual Physical Activity, which assesses regular physical activity (8). It continues with a set of five questions about smoking habits based on the Fagerstrom Test for Nicotine Dependence questionnaire (9). Then, respondents are requested to selfreport estimated weight and height and, after this, anthropometric indicators are measured objectively by trained interviewers (registering weight, height, waist and hip measurements). The interview ends with a semi-quantitative food-frequency questionnaire with 74 items.

The BMI cutoffs for overweight and obesity categories used here follow the International Obesity Task Force $(1,2)$. 
Table 2 Sample characteristics of 2003-2005 survey $(n=6411)$

\begin{tabular}{|c|c|c|}
\hline & $\begin{array}{l}\text { Women \% } \\
57.8(51.7)\end{array}$ & $\begin{array}{l}\text { Men \% } \\
42.2(48.3)\end{array}$ \\
\hline \multicolumn{3}{|l|}{$\mathrm{Age}^{\star}$} \\
\hline $18-19$ & $6.0(4.8)$ & $3.8(5.1)$ \\
\hline 20-29 & $31.8(23.5)$ & $26.7(24.8)$ \\
\hline 30-39 & $23.2(22.8)$ & $21.8(23.3)$ \\
\hline $40-49$ & $19.0(21.4)$ & $20.2(21.2)$ \\
\hline 50-59 & $13.9(18.8)$ & $17.6(17.7)$ \\
\hline $60-64$ & $6.2(7.8)$ & $9.9(7.9)$ \\
\hline \multicolumn{3}{|l|}{ Educational level $^{\dagger}$} \\
\hline Low level & 25.6 & 23.2 \\
\hline Medium-low level & 14.8 & 18.6 \\
\hline Medium-high level & 29.3 & 29.5 \\
\hline High level & 30.3 & 28.8 \\
\hline \multicolumn{3}{|l|}{ Professional status } \\
\hline Professionally active & 67.8 & 78.2 \\
\hline Student & 15.2 & 12.5 \\
\hline Pensioners & 3.8 & 4.7 \\
\hline Housekeeper & 7.7 & 0.3 \\
\hline Unemployed & 5.6 & 4.3 \\
\hline
\end{tabular}

*Population distribution according to the 2001 Census in brackets. ‘'Low level' includes: up to the 6th year of school; 'Medium-low level' includes: from the 6th year to the 9th; 'Medium-high level' includes: from the 9th year to the 12th; 'High level' includes: more than the 12th year of school.

Table 2 summarizes the demographic characteristics of the data collected up to June 2005. Comparing this sample with the population, women are over-represented. In fact, women represent $57.8 \%$ of the sample instead of the $51.7 \%$ existing in the total Portuguese population (4).

Although results from this 2003-2005 survey are still preliminary and some geodemographic deviations still remain, the size of the sample is already large enough to allow the assumption that the overall prevalence of overweight/obesity registered thus far $(52.4 \%)$ will not change significantly (Table 3). Consistent with 1995-1998 data, the prevalence of overweight/obesity among men is higher $(59.5 \%)$ than among women $(47.2 \%)$. When we consider only obesity categories, the prevalence in the overall sample is $13.8 \%$. Attending to these two epidemiological assessment moments, we are led to conclude that BMI categories prevalence did not change significantly. Anyway, according to these data, overweight/obesity prevalence increased from $49.6 \%$ to $52.4 \%$ over the last decade. Such an increase seems to result mainly from a shift from normal to overweight categories.

As can be seen in Fig. 1, the mean BMI by age increases in a somewhat linear way with age of participants till around 55 years old. After this age, there is a tendency towards a slight decrease in BMI mean values. When we look to the prevalence of BMI categories by age group (Fig. 2), it is striking that $8.0 \%$ of 18 - and 19 -year-olds
Table 3 Prevalence of BMI categories in adults (18-64 years old) in 2003-2005 survey

\begin{tabular}{|c|c|c|c|c|c|c|}
\hline & \multicolumn{2}{|c|}{ Women } & \multicolumn{2}{|l|}{ Men } & \multicolumn{2}{|l|}{ Total } \\
\hline & $n$ & $\%$ & $n$ & $\%$ & $n$ & $\%$ \\
\hline Low $(<18.5)$ & 126 & 3.4 & 27 & 1.0 & 153 & 2.4 \\
\hline Normal (18.5-24.9) & 1830 & 49.4 & 1069 & 39.5 & 2899 & 45.2 \\
\hline Overweight (25.0-29.9) & 1256 & 33.9 & 1216 & 44.9 & 2472 & 38.6 \\
\hline Obesity I (30.0-34.9) & 371 & 10.0 & 341 & 12.6 & 712 & 11.1 \\
\hline Obesity II (35.0-39.9) & 89 & 2.4 & 49 & 1.8 & 138 & 2.1 \\
\hline Obesity III ( $\geq 40.0)$ & 33 & 0.9 & 5 & 0.2 & 38 & 0.6 \\
\hline Total & 3705 & 100.0 & 2706 & 100.0 & 6411 & 100.0 \\
\hline
\end{tabular}

Table 4 Waist circumference in 2003-2005 survey

\begin{tabular}{llll}
\hline & $\begin{array}{l}\text { Women \% } \\
(n=3705)\end{array}$ & $\begin{array}{l}\text { Men \% } \\
(n=2706)\end{array}$ & $\begin{array}{l}\text { Total \% } \\
(n=6411)\end{array}$ \\
\hline $\begin{array}{l}\text { Waist circumference } \\
\text { Increased risk ( } \geq 80 \mathrm{~cm} \text { for } \\
\text { women; } \geq 94 \mathrm{~cm} \text { for men) } \\
\begin{array}{c}\text { Very increased risk ( } \geq 88 \mathrm{~cm} \\
\text { for women; } \geq 102 \mathrm{~cm} \text { for } \\
\text { men) }\end{array}\end{array}$ & 19.6 & 50.8 & 45.6 \\
\hline
\end{tabular}

have low weight. However, this high prevalence of low weight decreases to half in the 20- to 29-year age group. From this point onwards, there is a pronounced decrease in normal weight, resulting in an increase of overweight/ obesity categories - with a maximum of $49.9 \%$ of overweight in the 60-64 age group and a maximum of $23.0 \%$ of obesity in the 50-59 age group (this is also the age group where the combined prevalence of overweight and obesity is higher: $72.8 \%$ ).

Damage to health caused by overweight and obesity is not related only to the BMI but also to the distribution of fat tissue (morphologic type of obesity). Considering this, waist and hip measurements are being taken in the ongoing survey. Data already collected are summarized in Table 4. A total of $45.6 \%$ of the sample $(50.8 \%$ of men) has an increased health risk because of high waist circumference.

\section{Prevalence in children}

Padez et al. (10) conducted a recent and pioneering nationwide representative survey using objective anthropometric measurement. They assessed the prevalence of overweight and obesity in Portuguese children between the ages of 7 and 9 years, following the International Obesity TaskForce cutoffs (11).

The sample consisted of 4511 children (2274 girls and 2237 boys) attending public schools. The participating 


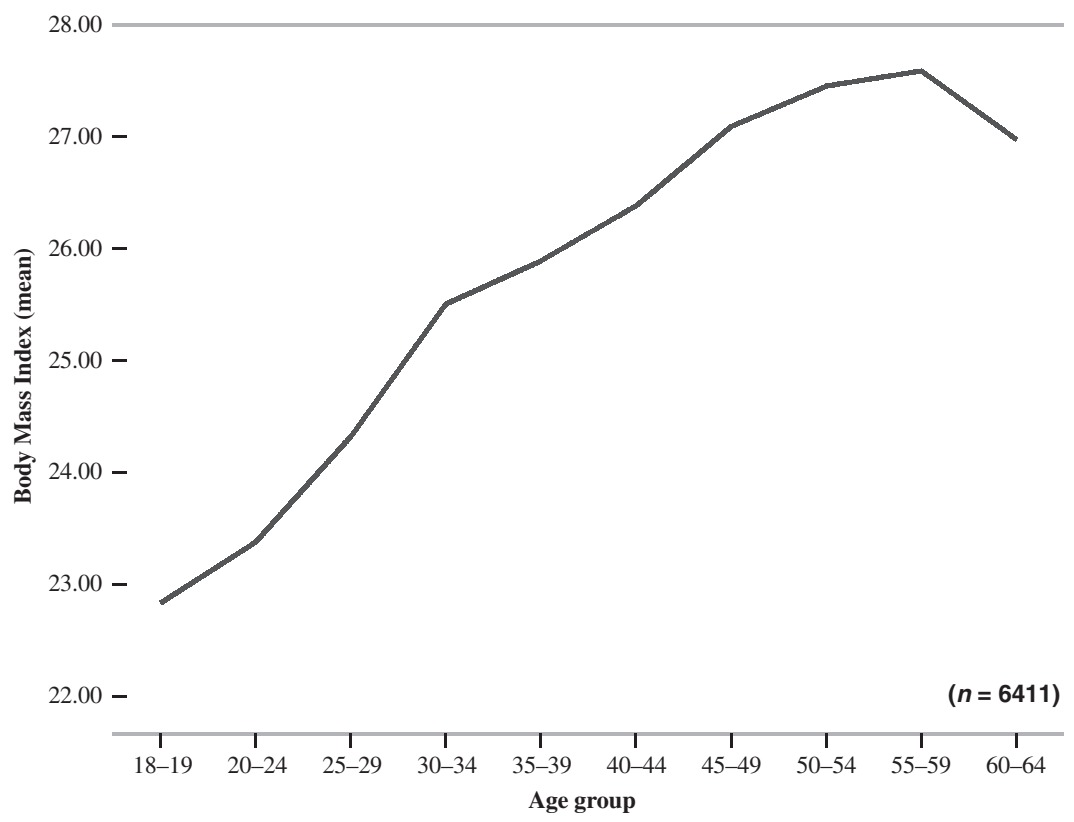

Figure 1 Mean body mass index by age group (2003-2005).

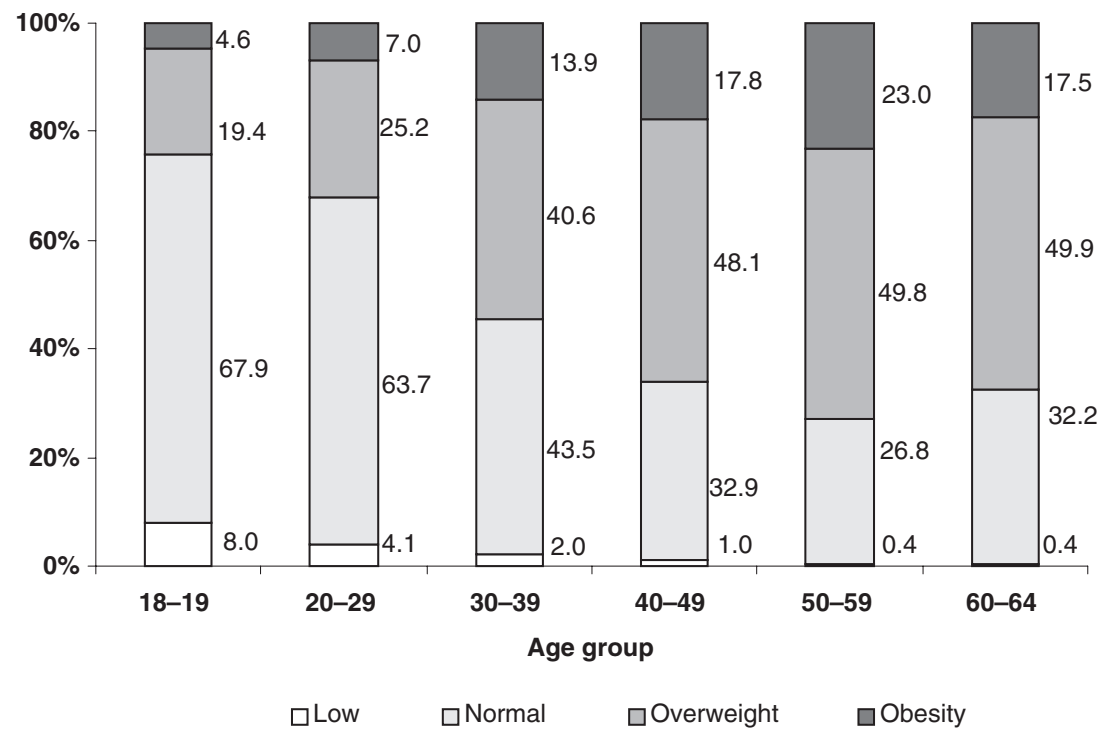

Figure 2 Body mass index categories prevalence by age group (2003-2005). schools were randomly selected in each district. In each school, the sampling followed a simple randomization process stratified by age. The authors found a prevalence of overweight/obesity of $31.5 \%$ (of these, $11.3 \%$ were classified as obese). Overall prevalence of overweight/obesity in girls was higher $(33.7 \%)$ than in boys $(29.4 \%)$. This study shows that the prevalence of overweight/obesity in Portuguese children is high when compared to other European countries, following the trend of other socio-cultural similar countries such as Spain, Italy and Greece. The authors highlight the strong increase in BMI among children between 1970 and 2002, making Portugal the European country with the second highest prevalence of childhood overweight/obesity (immediately after Italy - 36\%).

\section{Discussion}

More than half of the adult population and more than 30 per cent of children between the ages of 7 and 9 years have unhealthy weight. Even more serious is the fact that overweight/obesity prevalence is rising in time. In comparison with the other Iberian country (Spain), Portuguese prevalence of obesity does not differ too much. In fact, this is a similar scenario to most developed countries where over- 
weight/obesity prevalence is known. Such an epidemiologic context points to the urgent need for more effective preventive strategies with special emphasis on target populations such as children and adolescents.

\section{Conflict of Interest Statement}

No conflict of interest was declared.

\section{Acknowledgements}

We would like to thank Roche Farmacêutica Química, Lda. for all logistical and additional financial support. Supported by: Sociedade Portuguesa para o Estudo da Obesidade. Contract grant sponsor: Fundação para a Ciência e a Tecnologia POCTI/ESP/40913/2001/FEDER.

\section{References}

1. WHO. Obesity: Preventing and Managing the Global Epidemic. Report of a WHO Consultation on Obesity. World Health Organization: Geneva, 1997.

2. WHO. Obesity: Preventing and Managing the Global Epidemic. Report of a WHO Consultation on Obesity. World Health Organization: Geneva, 2000.
3. Martinez JA, Moreno B, Martinez-Gonzalez MA. Prevalence of obesity in Spain. Obes Rev 2004; 5: 171-172.

4. Instituto Nacional de Estatística [Portuguese National Statistical Institute]. Censos 2001: Recenseamento Geral da População e Habitação. Instituto Nacional de Estatística: Lisboa, 2001.

5. do Carmo I, Carreira M, Almeida MD, Gomes L, Almeida Ruas M, Lima Reis JP, Medina JL, Galvão-Teles A. Estudo da prevalência da Obesidade em Portugal (EPOP). Notícias Obesidade 2000; 8: 3-9.

6. do Carmo I, Carreira M, Almeida D, Reis L, Medina L, Galvão-Teles A. Prevalence of obesity in portuguese population. Int J Obes 2000; 24(Suppl.1): S91.

7. Marques-Vidal P, Dias CM. Trends in overweight and obesity in Portugal: the National Health Surveys 1995-6 and 1998-9. Obes Res 2005; 13: 1141-1145.

8. Baecke JA, Burema J, Frijters JE. A short questionnaire for the measurement of habitual physical activity in epidemiological studies. Am J Clin Nutr 1982; 36: 936-942.

9. Heatherton TF, Kozlowski LT, Frecker RC, Fagerstrom KO. The Fagerstrom Test for Nicotine Dependence: a revision of the Fagerstrom Tolerance Questionnaire. Br J Addict 1991; 86: 11191127.

10. Padez C, Fernandes T, Mourão I, Moreira P, Rosado V. Prevalence of overweight and obesity in 7-9-year-old Portuguese children: trends in body mass index from 1970-2002. Am J Hum Biol 2004; 16: 670-678.

11. Cole TJ, Bellizzi MC, Flegal KM, Dietz WH. Establishing a standard definition for child overweight and obesity worldwide: international survey. BMJ 2000; 320: 1240-1243. 